The patient soon recognizes the beneficial influence of the ice. Even young children, after the first few minutes, become easily accustomed to the cold, and will not consent to its removal. When it has been removed for an interval they will sometimes ask that it may be reapplied. A boy of 7 under my care at St. Mary's refused to allow his icebag to be taken away. To the inquiry, "Why not?" he answered, "Because I like it." To the further inquiry, "Why do you like it?" he replied, emphatically, "Because I $d o$. ."

The chief difficulty about the application of the icebag is to secure it from shifting its position when the patient turns in bed. This may be accomplished by passing the screw top of the icebag through a hole in a binder which is loosely passed round the chest and secured by safety pins. Sometimes it may be desirable to prevent its slipping downwards by securing it by a light bandage from behind the patient's neck. An excellent method used at the Hospital for Sick Children is by a vest with armholes, and a third hole over the cardiac region, made of domett, and fastened round the neck with a tape, and below the icebag by a safety pin.

The outline of the precordial dullness should be marked on the skin in blue for the guidance of the nurse. The icebag will require to be refilled about every hour and a-half, the hot-water bottles every three hours.

It is well to have a second icebag in use, so that itcan be filled and applied as soon as the first is removed. In filling the icebag, be careful to press out the air as much as possible before screwing on the top. The hot-water bottles should not all be removed from the bed at the same time, unless others are at once substituted. The patient's temperature should be taken every two hours, also his pulse-rate and respirationrate, and the result recorded on a chart. The nurse must see that the icebag does not leak, that its top is firmly screwed down to the "washer," and that it is surrounded by cotton wool or a soft towel to absorb the moisture from the air which tends to condense on its surface. But nothing should intervene between the icebag and the patient's skin.

When the nursing can be thoroughly trusted, as in a hospital, the icebag may often, with great benefit to the patient, be applied continuously for many days, provided that the condition of the right auricle be carefully watched, and the lower limbs be kept thoroughly warm. Occasionally it may be wise to remove it for a few hours during the night, especially between midnight and six o'clock in the morning. If the nurse has had little experience of children, or is not accustomed to the use of the icebag as here recommended, it will be safer to apply it only during the daytime. If no skilled nursing is available, the treatment may still be used during the daytime if the mother is intelligent and careful, and the practitioner explains to her the use of the clinical thermometer, and tells her precisely what to do. If the practitioner is in doubt whether the icebag ought to be continued, let him order its removal for one hour, and thereafter its application for two hours, and so on.

It is sometimes possible to continue the application of ice to the precordial region even though the temperature have fallen below the normal. A child under my care at St. Mary's some years ago, whose pericarditis had improved under this treatment, was found one evening to have signs of pneumonia at the base of one lung. Twice before I had met with this in young children suffering from pericarditis and treated with ice; in each case when the pneumonia appeared I removed the icebag from the heart, fearing that it might be doing larm. Both patients died. When in this third rase I again found pneumonia appearing in a case of pericarditis treated with ice, I determined to persevere in my plan of treatment and to push it further. Two more leeches were applied, and a second icebag was placed over the inflamed lung, that over the heart being retained. I should hardly have ventured on this but for the kind willingness of my house-physician, Dr. Gordon (now medical superintendent of the City Fever Hospital, Manchester), who remained by the child's bedside and was able to keep the two icebags in position during the whole night, though the temperature was at times subnormal When I saw the child next morning the signs of commencing nneumonia had disappeared and recovery was uninterrupted. This case proved to me that with adequate care it is possible to use the ice in pericarditis when the temperature is low. But in the later stages of a pneumonia this is not the case.

The treatment of rheumatic pericarditis by large and frequent doses of sodium salicylate and sodium bicarbonate, with the local application of jce over the heart, is amply justified by its results. Cases treated without ice, and with .inefficient médication, are very apt to linger in recovery, and to result in a permanently dllated and crippled heart. Relapse of rheumatism frequently occurs and ends the case in a year or two. Even apart from a probable relapse, the heart is often so severely injured that symptoms of failure of the circulation develop early. Treatment of the kind here advocated greatly diminishes the tendency to rheumatic relapse; it checks the inflammation, increases the vigour of the muscular fibre, and diminishes the dilatation, thus enormously assisting the forces that make for repair. The practical difference to the patient is often a difference of many years of life.

In the milder cases of rheumatic carditis, those in which there is no evidence of pericarditis, similar treatment (with out the bleeding) may be used with great advantage, thougl the effect is less striking. Since in every case of rheumatism, acute or subacute, there is dilatation of the left ventricle, as may easily be proved by careful percussion, it is clear that there is always some affection of the cardiac wall, either toxic or inflammatory. The cardiac muscle is weakened, as is proved by the altered first sound, the diffused impulse, and the enfeebled pulse-wave. A murmur indicative of endocarditis may or may not be present. Here, then, as really though not so forcibly as in pericarditis, there is a calt for antirheumatic medication and for means of repressing local inflammation. I believe that if this method of treatment were universally adopted in the slighter attacks of rheumatism it would very greatly diminish the number of cases of mitral regurgitation and stenosis in adults, and would prevent an enormous amount of cardiac misery.

REFERENCE

1 BRItish Medical JouRnaL, September igth, rgo3, p. 659 .

\section{THE MECHANISM OF RESPIRATION IN PNEUMOTHORAX:}

BY ARTHUR EDMUNDS, M.B., B.S., B.Sc., F.R.C.S , Sambroke Surgical Registrar, King's College Hospital; Assistaut Demonstrator of Physiology, King's College, London.

(From the Plyysiological Laboratory, King's College, London.)

PNeumothorax with an external opening is far from an uncommon condition, either as the result of an injury or of surgical interference, such as, for example, in cases of empyema, or tumours of the thoracic wall. If an opening communicates between the pleural cavity and the externat air, the respiratory mechanism lacks an all-important factor - the difference of pressure in the lung and pleura is abolished, so that the elastic tension of the lung has free play to. cause collapse of that organ. It is, however, a matter of common experience that one pleura may be opened witls comparative impunity, and that in these cases the lung does not collapse, but in the majority of cases is forced into contact with the chest wall, and, if not injured itself, will rapidly take on its function once more. The means whereby this is accomplished has been a matter of discussion, and the present state of our knowledge on this point is summarized by West. ${ }^{1}$ This author states that there is a pressure in thetubes of the lungs during expiration, amounting to from $1 \frac{1}{2}$ to $2 \mathrm{~mm}$. of mercury while during inspiration there is a negative pressure of abont $\frac{1}{2} \mathrm{~mm}$. of mercury. He is of opinion that this pressure during expiration has some effect. in expanding the lung on the affected side, but is uncertain as to the amount of expansion which is possible under the influence of a pressure of this magnitude. He further notes that although the expansion of the lung may at first be to at considerable extent due to the violent respiratory movements and to the cough which frequently follows the operation, yet that there must be some other explanation, inasmuch as this expansion may take place without any of these violent. respiratory movements, and without any cough.

As far as I have been able to ascertain, no satisfactory explanation has been put forward to explain this phenomenon. and it was to attempt to throw some light on this problem that the present series of experiments were undertaken.

There is one factor in respiration which cannot have escaped notice, but which so far has escaped emphasis, and this is the very important resistance to the outflow of the air which can be offered by the vocal cords and fauces generally.

The following are brief notes of an illustrative case, for permission to publish which I am indebted to Mr. Burghard, surgeon to the Paddington Green Hospital for Children, and to Dr. Alexander Morison, Physician to the hospital. 
A child was admitted to the hospital suffering from a large pneumococcus empyema. This was opened, and a rib resected. The wound contracted to a sinus, but did not heal. It was therefore decided to send the child to the convalescent home, and then to perform an Estlander's operation.

An incision was made along the chest wall, and portions of the second to the ninth ribs were removed from the anterior axillary line to the epiphysial line. The lung was then seen to be bound down by a dense inflammatory membrane. This was readily stripped off (decortication of the lung), and the visceral pleura was found to be practically normal. It was noticed when the membrane was removed that the patient's respiration took on a distinctly altered character; it became triphasic ; the first phase was an inspiratory effort; this filled the lung on the sound side with air, the lung on the affected side collapsed. The second phase was an expiratory effort, and during this time the affected lung was seen to fill with air, and to struggle in its effort to expand against the remaining bands of adhesions. The air which flled this lung was forced over from the healthy lung, as it was unable to escape to the exterior, owing to the closure of the glottis. In the third phase the glottis opened, the expiratory effort continued, and air passed to the exterior from both lungs. The passage from the second to the third phase was marked by a distinct grunt. The three phases may be briefly termed inspiration, distribution, expiration.

This condition of affairs persisted as long as the child lived. Death was due to the spread of infection from the pleura to the pulmonary tissue, setting up multiple abscesses in the substance of the lung. Pecortication of the lung in such cases has the advantage of allowing the affected lung to play its part in respiration, but is attended with the risk of infecting the lung tissue anew.

It is the conditions of this case which $I$ have attempted to reproduce in animals, in order to study the mechanism with greater precision. My experiments have been made mainly on cats, but I have used the rabbit and monkey as well The animals were anaesthetised with either A.C.E. mixture or ether, and were killed before they recovered from the anaesthetic. The trachea was exposed and the recurrent laryngeal nerves isolated on ligatures, so that they could be cut when required. A cannula was placed in the carotid artery and connected to a mercury manometer in those experiments in which it was desired to record the blood pressure. A lateral tube was connected to the trachea either by inserting the crosspiece of a short $T$ made of glass or by tying the ends of the crosspiece of the $T$ to the two segments of the divided trachea. The stem of the $T$ was connected to a Marey's tambour which was calibrated and served as a delicate manometer. The movements of the lever of the tambour were traced upon a revolving drum.

In my later experiments I succeeded in keeping the vocal cords under observation by the aid of an endoscope. The following was the device adopted: The trachea was exposed and cut across, care being taken not to injure the recurrent laryngeal nerves. A glass tube (Fig. I A) about 4 in. long was inserted into the laryngeal end of the divided trachea. Near the end of this tube a side tube (B) was tied into the pulmonary end of the trachea.

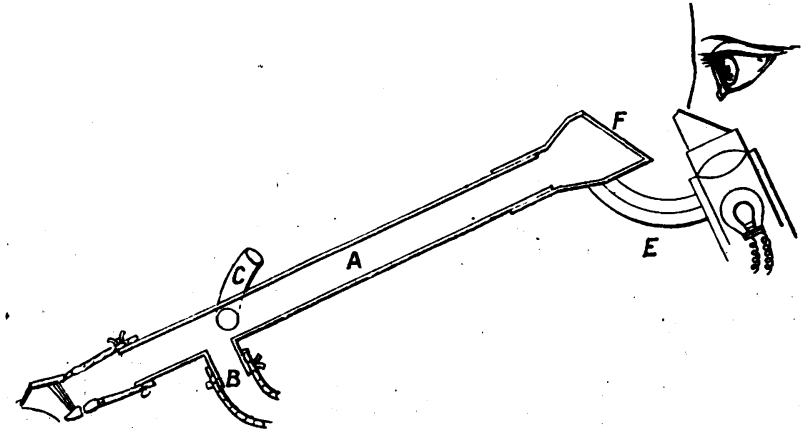

Fig. r.-Diagrammatic section of eudoscope adapted for observation of the vocal cords.

Another lateral tube (c) a little higher up was connected as before to a recording. tambour. The free end of the tube (A) was closed with an air-tight joint with a Schall's electric endoscope, which illuminated (A) and the vocal cords at its far end. The endoscope consists of an electric lamp surrounded by a cooling jacket. It is so fixed that the light is reflected by a right-angled prism through a glass plate (F) placed obliquely as shown in the diagram. Respiration by this means is not interfered with, and the vocal cords can be inspected from below during the whole experiment:

Having placed this apparatus in position, the skin over the chest wall was incised in order to allow of the chest being subsequently opened with a minimum of interference with the animal. In some of the experiments a brass tube $I$ in. in diameter and $\frac{3}{4}$ in. length was tied into the muscular and fascial tissues of the chest wall. This tube had two side branches and could be closed by a glass plate. Thus, if an opening was made into the thorax at the bottom of the brass tube, it was possible to close the pleural cavity at will, to connect it with the tambour, or to inflate it with air or fluid.

I have not made a long series of observations on arterial blood pressure, but in the cases where I have recorded it I have found that there was a slight fall on opening the chest which was followed by a rise.

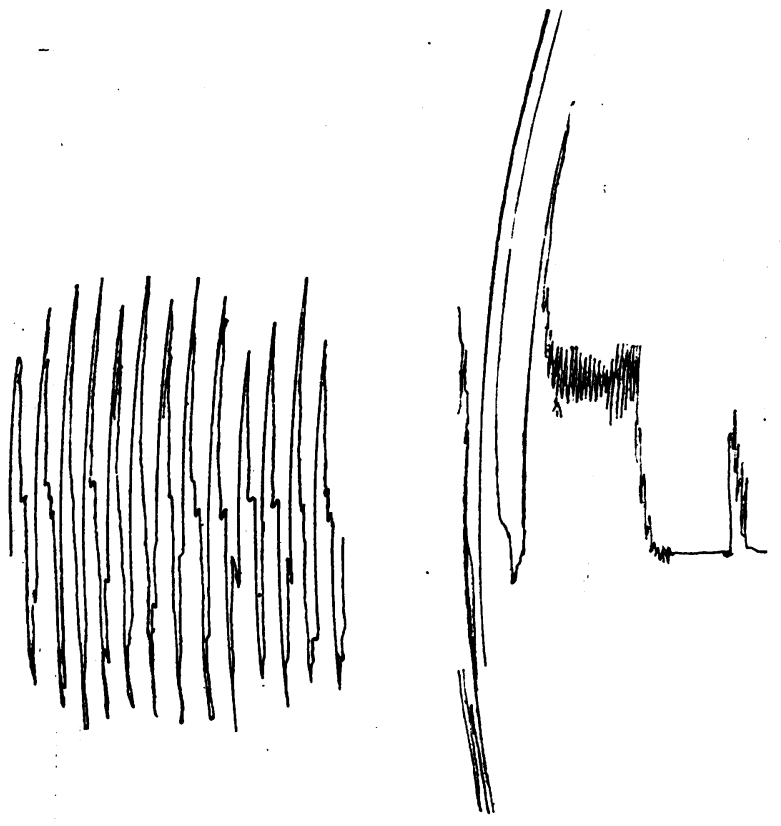

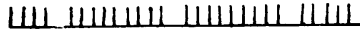

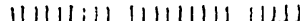

Fig. 2.-Tracing of intratracheal pressure in a cat. Normal tracing ; cardio-pneumatic waves are superposed on the tracing. In this and all subsequent tracings the time is indicated in seconds and the reading is from left to g. 3.-Tracing from the same animal after the establishment of a pneumothorax on one side. Note the sustained condition of positive pressure and the greater prominence of the cardio-pneu matic curve.

The normal intratracheal pressure recorded in the manner described (see Figs. 24,10 ) shows variations in both positive and negative directions; the positive change which accompanies expiration is represented by the upstroke and the negative which culminates in inspiration by the downstroke; the zero position of the tambour lever is shown in some of the tracings by a horizontal line which divides the record into approximately equal parts, but, as a rule, the change in the positive direction is the greater. The absolute measurement on Fig. Io amounted to about 6 in. of water in both directions.

It will be noticed that in these tracings each curve has an acutely pointcd top - that is, after the positive change has, reached its height, no appreciable interval occurs before the pressure begins to diminish. In some cases cardio-pneumatic curves are seen superposed on the respiratory tracing (Figs. 2 and 3). In a few exceptional cases there was a slight pause when the rise of pressure was at its maximum. If the vocal cords are watched during such an experiment they are seen to be moving freely; the cat is a specially favourable animal for such observations. The cords never actually touch each other nor are they abducted out of sight.

When, however, the chest wall is perforated a totally different sequence of events is observed. The cords take on a more vigorous movement; at one stage they are approximated until they actually touch each other and at the opposite stage they are separated until they become invisible; at the same time the respiration is usually markedly slower. Corresponding to this a change takes place in the tracing of intratracheal pressure (Figs. 3. 5, and 6)

The top of the curves is no longer sharp, but distinctly flattened. This indicates that the increased pressure in the trachea is being maintained for a considerable time. In this condition the cardio-pneumatie curves are better se $\boldsymbol{n}$ (Fig. 3). During this period there may be an actual plateau, 


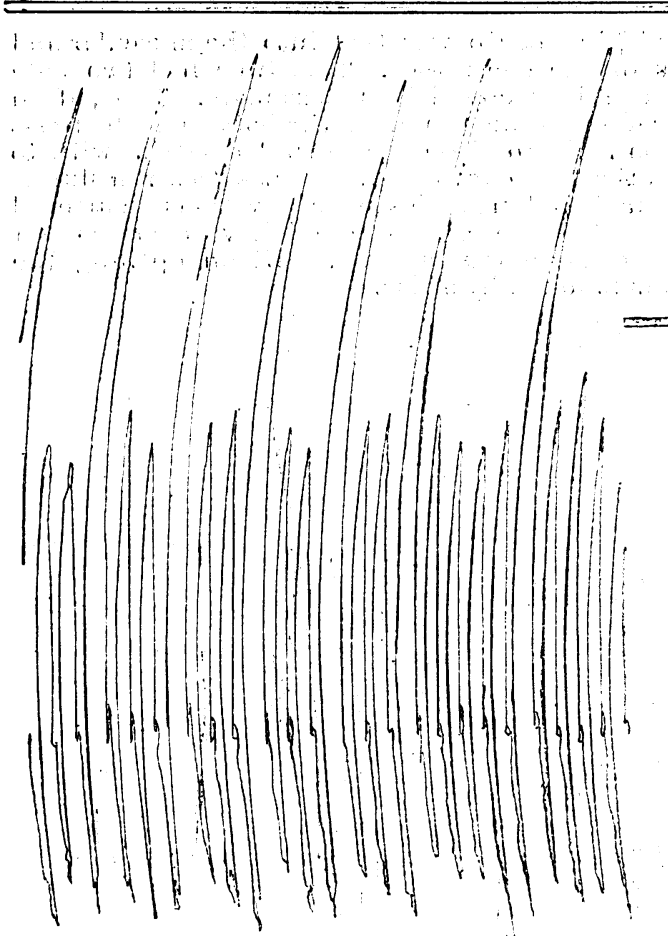

Fig. 6.-A still more marked example of the same condition in anotìer animal in which
the respiration was convulsive and extremely slow.

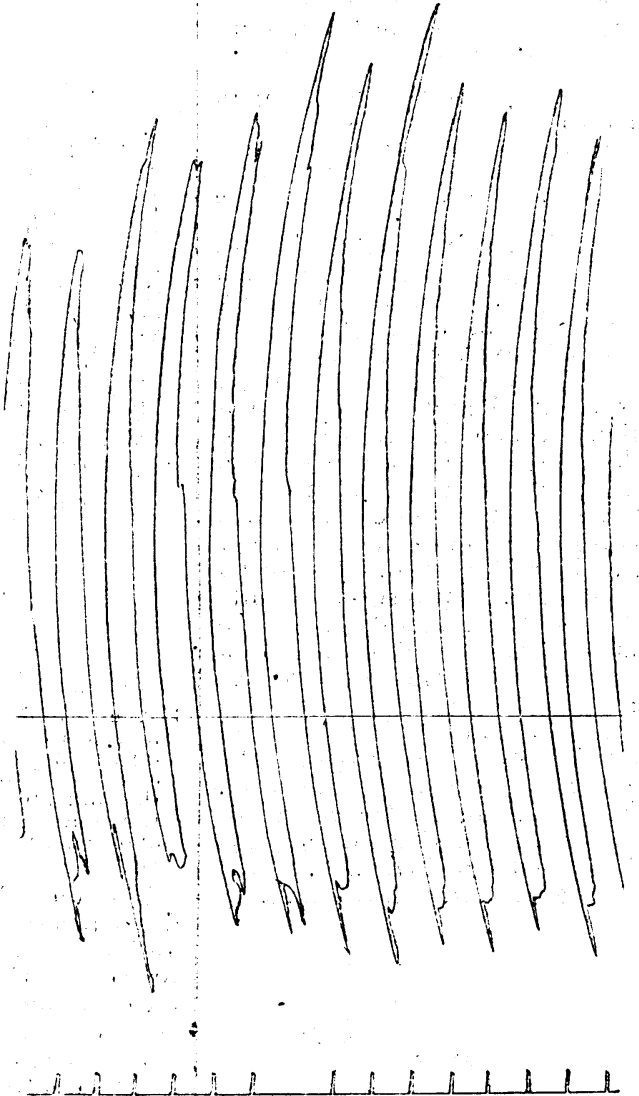

Fig. 7.-Normal intratracheal pressure-cat. or the sudden rise of pressure may be succeeded by a fall for a short distance, the pressure then remaining high and constant for some time.

The amount of negative pressure is markedly lessened ' and often almost. abolished. During the time that the intratracheal pressure is thus maintained the glottis is seen to be rigidly. closed, and the lung of the affected side is seen to become inflated with air, and in a successful experiment. will be brought right up to the chest wall.

This result has been constant in all the experiments that I have performed-I5 in number-with one exception. In this one case (Figs. 7 and. 8) the form of the tracing was practically the sameaiter the establishment: of the pneumothorax as before this operation was per-

formed. This exceptional case proved on further examination to be an instructive one, for it was founc that in this cat the whole of the pleurae were adherent, and there was also a patch of fibrinous deposit on the heart and pericardium.

Another slight modification of the usual course of events which I have occasionally observed consists of the abduction of the - rhythm is shown in this part of the traciugeculia larger movements occurred. when the cords were

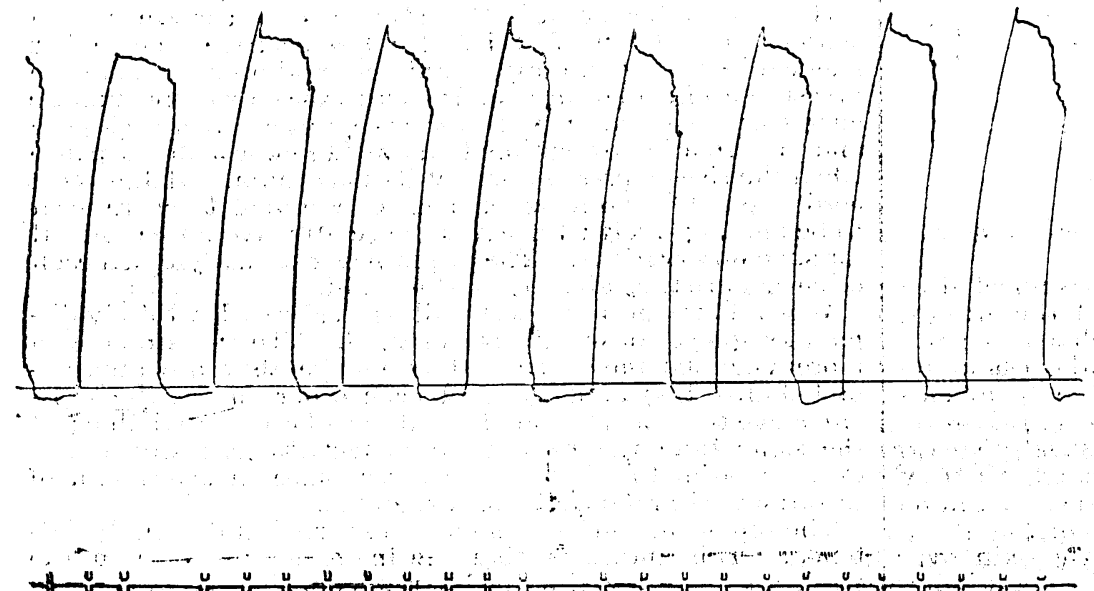

1) 5.-From another animal in which the sustained condition of positive, and the . diminution of megative pressure is very txpically seen. cords taking place in two successive steps
the cords after approximation are abducted to about midway between abduction and adduction, and then, after a short pause, ale fully abducted.

Division of the recurrent laryngeal nerves produced an effect which is shown in Figs. 10

to 14. Under these circumstances the parajysis of the larynx prevents the adduction of the cords being brought about, and so the intratracheal pressure cannot be suistained; in other 'words, the shape of the pressure curve once more approximates to the normal; this is naturally more marked : when both nerves are divided. .After a timel however, respiration becomes extremely embarrassed, extrinsic laryngeal and neck muscles are brought into play forcibly, and in a thin animal this suffices to force the cords : together' by: actually' bending the thyroid cartilages. The result is that the intratracheal pressure is once more sustained (Fig. 14), and with the endoscope the cords are seen to be in apposition 

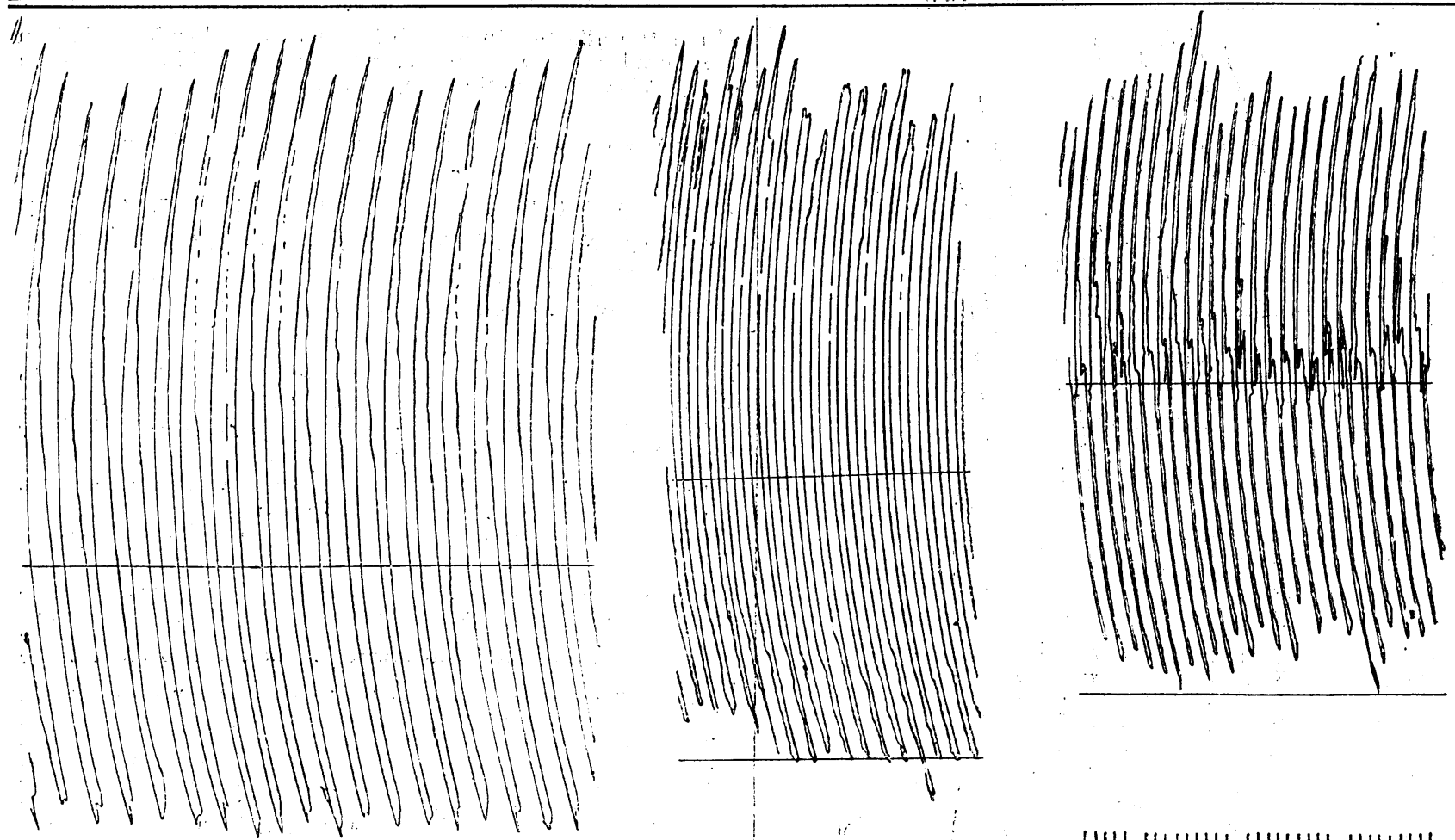

Z_A A

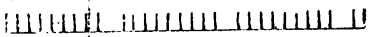

Fig. 8. - Tracing from same animal after opening one pleura. Fig. ro.-Normal intratracheal pressure No alteration in the chiracter of the curn
pleura found to be adherent on both sides.

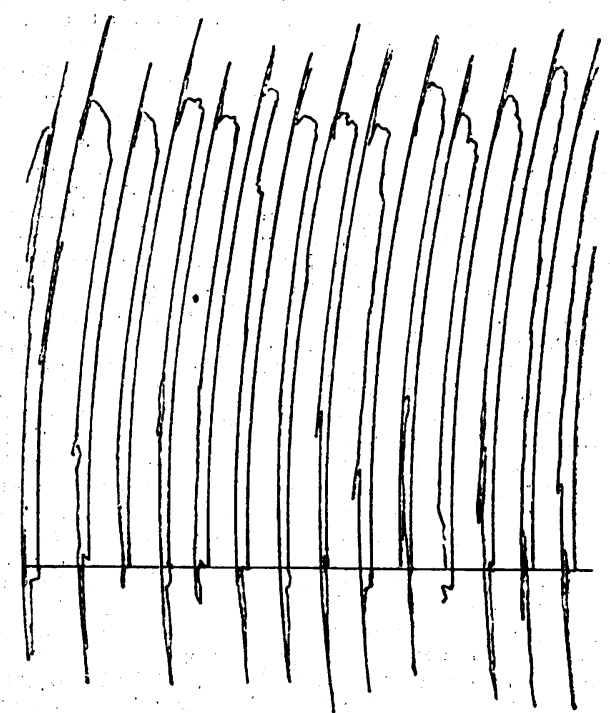

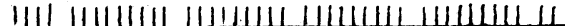

Fig. 9. $\rightarrow$ Intratracheal pressure in a cat witl a pneumothorax. In this instance the glottis was seen. Arst to absolutely close; then the cords were separated about hall way, and finally. they were absolutely abducted.

once mare during this time. The intrapleural pressure, which of course exhibits no variation when the chest is freely open, can be recorded in the manner already : desoribed when the chest is, partially filled with air. If under these circumatances the chest cavity

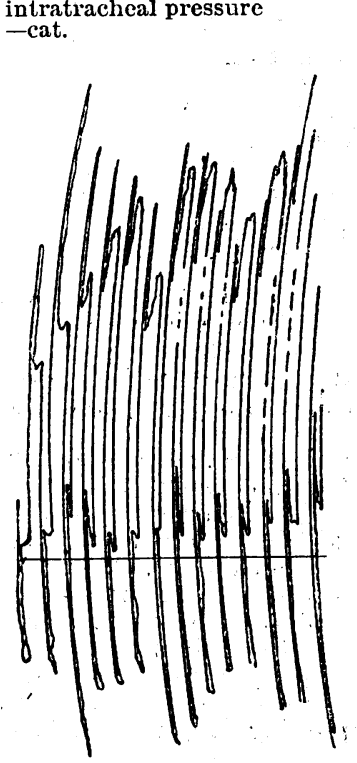

LiII 111 IIIII IIIIII) IIIIIII)

Fig. 13.-The same after division of the other nerve. The tracing now approxiinates to the normal.

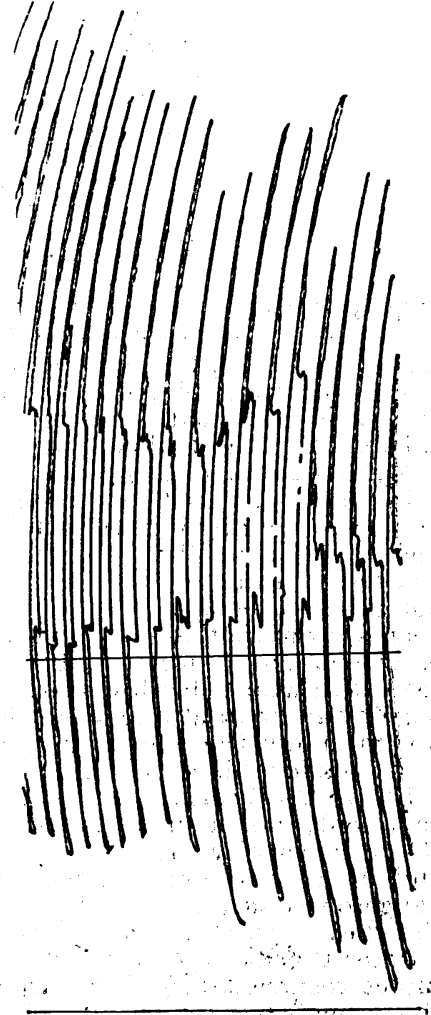

4IIII 11111111111111111

Fig. 1x.-Pneumothordx has now

been establishe 1,01 , the vight

side. Negative i $\mathbf{r}$ ssure much

essened, positive pressu

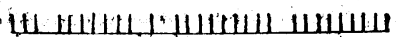
Fig. me same after division of 


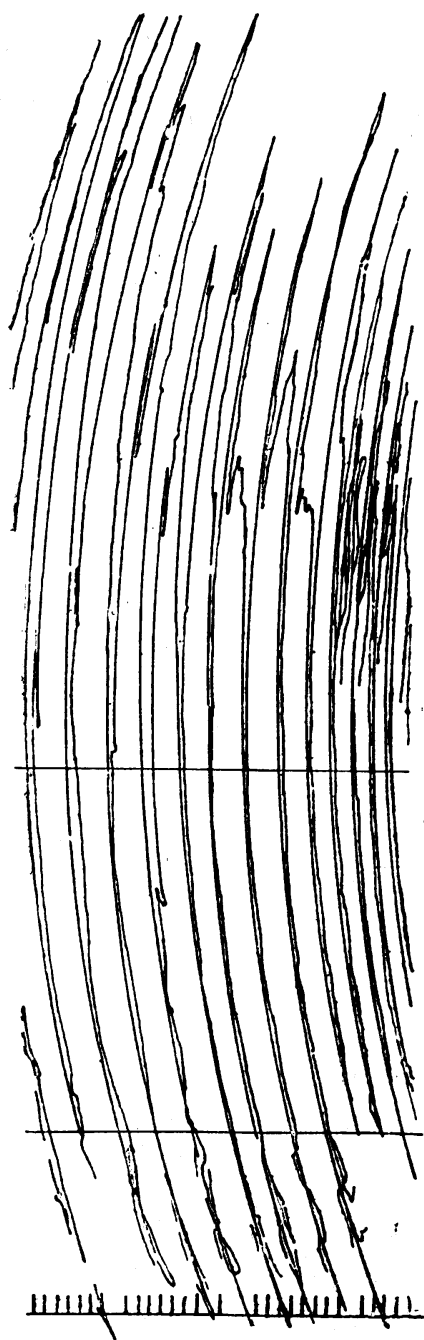

Fig. 14.- Later stage ; the vocal cords have been forced into apposition by the extrinsic muscles of the larynx and of the neck.

was again closed, I noticed that the respiratory waves on the blood-pressure tracing completely disappeared, although they were as well marked when the chest was freely open on one side, as in the normal condition.

My method of opening the pleural cavity allowed of fluid being easily injected into it, and $I$ found that it was easy to kill the animal by injecting fluid under the pressure of a few inches of water. Moreover, the injection of a few cubic centimetres of $\mathrm{I}$ in 20 carbolic acid was rapidly fatal. These two points are of considerable practical importance. It has long been known that forcible injection of the pleura in cases o empyema has often resulted in the death of the patient. The ease with which death is produced by reflex respiratory stoppage by an irritant like carbolic acid injected into a normal pleura shows the neeessity of employing only non-irritating solutions for this purpose.

I have a!'so been able to confirm in my experiments what is commonly noted in operations on the chest, that an anaesthetic is usually more potent when only one lung is acting and if in my experiments the anaesthetic was pushed dangerously far, I failed to produce the reflex mechanism of the glottis, which I regard as so all-important in these cases.

After the establishment of the conditions described with intact recurrent laryngeals, though the respiration is slowed, the animals breathed quite quietly, and though the air which was forced into the affected lung had been already once breathed, or at any rate had occupied the upper respiratory passages of the sound lung, there was never cyanosis or any other sign that aëration was insufficient.

If, in conclusion, we compare the typical case that I have described at the nutset, and which suggested to me the present investigation, with the an mals with which I sought to establish simi ar conditions, we see that in the main the mechanism by which the affected lung is inflated by overflow from that on the sound side, owing to expiratory efforts taking place with the glottis closed, is the same in both cases.

1 Article in Clifford Allbutt's System of Medicine, vol. v, p. 340 .

\section{TWO CASES ILLUSTRATING THE FALLACY OF CERTAIN PHYSICAL SIGNS IN DIAGNOSING ACUTE PERFORATED GASTRIC ULCER.}

\author{
BY W. HARLAND PEAKE, M.D., B.S.
} Hampstead.

THE two following cases may prove of especial interest to medical men in general practice whose lot it is to see cases of perforated gastric ulcer in the early stage, upon whose correct diagnosis so much depends.

CASE I.

Iistory. - I was called to see Mary H., aged 23 (formerly in domestic serve she had been living at home working at chicken stubbing, form of employment which entails sitting nearly all day. There was a history of dyspepsia of some months' duration, but there had never been any haematemesis or melaena as far as the patient knew. She had done her work as usual that day, and had taken a meal at 6 p.m., consisting of tea with bread and butter. At $9.30 \mathrm{p}$. she was seized with severe abdominal pain, and she vomited twice but there was no blood in the romit.

state on Examination.- The patient, who was not collapsed and was quite able to describe her symptoms, looked somewhat anaemic, and complained of severe pain in the upper part of the abdomen, whicl extended round both sides, and became worse every now and then. The abdomen was resonant, the liver dullness present, and there was tenderness on pressure in the epigastric region, with some resistance. The tongue was clean and moist, and the bowels had resistance. The tongue was clean and moist, and the bowels had
acted the day before, the motion being somewhat relaxed. The temperature was normal, the pulse 72 , regular and of good volume. The diagnosis seemed to be between some form of colic and gastralgia, due probably to a gastric ulcer; the absence of collapse, especially the good condition of the pulse combined with the presence of liver dullness seemed to negative perforation. Morphine having been procured seemed to negative perforation. Morphine having been procured one-sixth of a grain was injected into the skin of the abdomen at I p.m., when the pulse had not altered. Hot fomentations were ordered
to the abdomen, and it was arranged that word should be sent at 6 a.m. the following morning if the patient was no better. At that hour she was a little easier, so that, unfortunately, no message was sent until a m when the pain was returning as severely as before. sent until 9 a.m., when the pain was returning as severely as before. The condition then found was as follows: Abdomen somewhat dis pulse roo, temperature $100^{\circ}$. There had been no more vomiting, but some retching. As it was clear that the condition of peritonitis, the present, was due to a perforation which took place at 9.30 the previous evening, when the first very acute pain was felt, operation at home was sugested but declined; the patient, who assisted to dress herself, was suggested but declined; the patient, who assisted to dress herself, was (For the further notes or this case $\mathrm{I}$ am indebted to $\mathrm{Mr}$. Frederick Travers, Surgeon-at that time House-Surgeon-to the West Kent General Hospital, who performed the operation.)

Operation.-Upon arrival, at Ir.45 a.m., patient was very blue, cold, and collapsed, with hardly perceptible pulse. Hot bottles were applied, and the operation commenced at 12.45 , fifteen and a-quarter hours after perforation, the abdomen being considerably distended and tympanitic up to the fifth costal interspace on either side. Very little chloroform was required On opening the abdomen a quantity of gas escared. was required. On opening the abdomen a quantity of gas escaped, lympl. The perforation was about $\frac{1}{4}$ in. in diameter, cleanly punched out, and situated on the anterior surface of the stomach near the leseer curvature at the junction of the pyloric and middle thirds of the viscus; around it were several layers of thick lymph. Thick flakes of lymph were adherent loosely to the upper and lower surfaces of the liver, the under surface of the diaphragm and peritoneal surface generally. The lympl round the ulcer was eleared off, and the wall of the stomach folded and secured by a row of Lembert's sutures, a flap of the great omentum was turned up, and fastened over this by interrupted sutures. About two pints of fluid were removed from the peritoneal cavity, which was washed out with a solution of chinosol, in 2,000 and afterwards with sterilized water. A glass drainage tube was left in the lower angle of the wound. The patient had no mo re and hypodermic injections of strychnine were given, but she died at 3 a.m. the following morning.

\section{CASE II}

History.-On July 26 th, rgor, I was called to see Miss T., aged 23. She had suffered from dyspepsia for two or three years, characterized by pain and distension after meals, and often had to unfasten her clothes to obtain relief. Some time previously I had treated her for this at my surgery, and as slie had improved so quickly and markedly with dieting and bismuth I did not consider her case one of gastric u'eer. - Five day' before she had sustained a great shock and since tlren had eaten very little. At $8 \mathrm{a} . \mathrm{m}$. cn the morning of July $26 \mathrm{th}$, 